\title{
Verification of the Efficacy of the Special Water Shaped Charge Prototype
}

\author{
Stanislav Lichorobiec and Karla Barcova* \\ Faculty of Safety Engineering, VŠB -Technical University of Ostrava, Ostrava Vyskovice, Czech Republic \\ "E-mail: karla.barcova@vsb.cz
}

\begin{abstract}
On the basis of an analysis of terrorist attacks carried out worldwide, where in recent years a preference for the use of bulk explosives placed in vehicles prevails, effective protection against these malicious explosive-containing systems that have a single goal - to cause death and significant material damage in a large radius is dealt. These improvised explosive devices are, in pyrotechnical terms, ranked as one of the most effective weapons, with a highly destructive character of explosive effect. A special water shaped charge that is able to destructively disassemble a bomb without initiation has been developed as an effective invasive means of eliminating similarly designed terrorist explosives hidden in cars, a condition which allows for considerable variation in location.
\end{abstract}

Keywords: bulk terrorist charge, water shaped charge, improvised explosive device, cumulation

\section{INTRODUCTION}

The international situation and manifestations of terrorism on a global scale reveal that improvised explosive devices (IEDs) have become a very common weapon of the perpetrators of this type of crime. IEDs have been used for threatening, equity enrichment and extortion, as well as being an effective tool in implementing terrorist attacks using explosives under any pretext. At present, terrorist groups very often use largescale terrorist bombs where a large amount of explosives (tens to hundreds of $\mathrm{kg}$ ) is located in a motor vehicle, usually a van, which gives the explosives considerable flexibility in their transportation to the designated place. The explosives in the cargo area of the vehicle can be easily and relatively quickly moved to the location of the expected attack. A vehicle can hold a huge amount of explosives, and during explosion, scattered parts of its bodywork increase the fragmentation/ splintering efficiency of the attack. The detonation temperature of the explosives used has an effect on surrounding objects. The highly destructive nature of the effect of bulk charges stored in vehicles ranks this weapon among one of the most powerful and destructive. From a pyrotechnical point of view it is very difficult to intervene against this form of bomb attacks, especially for the following reasons:

(a) The vehicle loaded with a large amount of explosives may be secured against opening, and disposing of them simply by unloading is not possible,

(b) The charge may be planted at a time period specified in conditions while negotiating with terrorists and possibly even detonated by a remote-controlled detonator.

For these reasons, it is not possible to remain in the vicinity of such a vehicle too long while attempting a more detailed identification of the explosive device and its disposal.
The charge must be removed aggressively via a destructive invasive method that separates the explosives placed in the vehicle from the initiation system before it is initiated.

The best method for a non-explosive disposal of bulk charges in this case appears to be a deactivation using shaped charges, which have a cumulative space filled with water - the use of so-called special water shaped charges (WSC), which must meet two basic conditions:

(a) Break the metal wall of the vehicle's bodywork using a directed water jet.

(b) Substantially disturb the bulk charge stored in the vehicle, move and disperse it outside the vehicle, thereby separating it from the initiation system and preventing an explosion.

Currently, however, there is no ordinance for a systematic disposal of explosives. For the liquidation of smaller bombs, so-called improvised explosive device disposals (IEDDs) are commonly used to neutralise IEDs, that is, robotic systems with remotely controlled articulated arms ${ }^{1,2}$, or special single function disrupter robots ${ }^{3}$. A wide range of system designs consist mainly of mathematical modelling and simulations. Shaped charges are very suitable for the disposal of bulk charges in vehicles, as they destructively separate the explosive from the initiator system in a short time. Water cumulative charges are used for the disposal of bulk charge in vehicles mainly in the USA, but these modular systems are very expensive and often require a longer preparation time for use $\mathrm{s}^{4}$.

\section{THE DEVELOPMENT OF A SPECIAL WATER SHAPED CHARGE PROTOTYPE}

The aim of this article is the experimental development proposal for a special water shaped charge as an effective 
means of deactivation and invasive dismantling of an IED in the form of a bulk explosive placed in a van. The purpose is therefore to create a simple, inexpensive, yet effective system from commercially available means.

It is possible to store up to $1800 \mathrm{~kg}$ of explosives in a van, the lethal detonation efficiency radius of which can be empirically expressed as directly proportional to the square root of the weight of the applied charge, thus $r_{\text {lenthal }} \approx \sqrt{m}$. In the case of the considered amount of explosives $m=1800 \mathrm{~kg}$, this would entail a circle with a radius of approximately $43 \mathrm{~m}$, in which death would occur with 100 per cent certainty. ${ }^{5}$

The maximum shock wave pressure generated during the detonation of the explosive used in this case will operate with a 100 per cent destructive effect on all surrounding objects within the radius of efficiency, which is proportional to the cube root of the weight of detonating explosives multiplied by a coefficient of 0,6 for the explosive trinitrotoluene (TNT), thus $r_{\text {destruction }} \approx 0,6 \sqrt[3]{m}$. Upon detonation of this amount of explosives, the total destruction of buildings from any material within a radius of $7.3 \mathrm{~m}$ would occur. It is possible to determine the radius of safety for the said explosion of a bulk charge of $1800 \mathrm{~kg}$ from the empirical relation via a comparative computation for the distances to which individual dangerous effects determined by the risk coefficient would apply. The radius of safety is directly proportional to the product of $k_{r} \approx \sqrt{m}$, where the risk coefficient for the effects of masonry fragmentation has a value of 22.5; the effects of the shock wave are fixed at a value of 100 . The radius of safety for masonry fragments in this case would be $955 \mathrm{~m}$ and $4243 \mathrm{~m}$ for injuring effects of the shock wave ${ }^{6,7}$. The detonation pressure needed to destroy brick buildings ranges between $30 / 40 \mathrm{kPa}$, in the case of concrete structures it is about $53 \mathrm{kPa}$. By comparing these mathematically documented data it is clear that a van laden with such an amount of explosives will pose a huge threat to the vicinity in terms of both lethal effects and creating considerable economic damage. The destructive effect of the detonation pressure to buildings in the epicenter of the explosion will cause their complete destruction, and this will move into a state of severe damage in the radius distance of about 60 meters, including the origin of subsequent fires fueled by the explosion temperature of the explosive used. The deadly and harmful effects caused by the fragmentation of brickwork and the shock wave would occur up to a distance of about $4 \mathrm{~km}^{8,9}$.

The mathematical calculation of the acceleration of the metal wall by explosive detonation was derived from the comparison of an asymmetrical sandwich construction. The sandwich is assembled in the following sequence - metal/ explosive/seal.

There will be a water surface in the cumulative area of explosives located behind the metal plate, followed by an explosive, which will be sealed from the rear by a seal in the form of another body of water. The schematic representation of the sandwich arrangement is as shown in Fig. 1.

For the construction of a genuine water shaped charge in the form of an asymmetrical sandwich, a cumulative volume of about 201 of water (blue segment $\mathrm{K}$ ) should be used, and this will be placed in front of the vehicle body (black segment K),

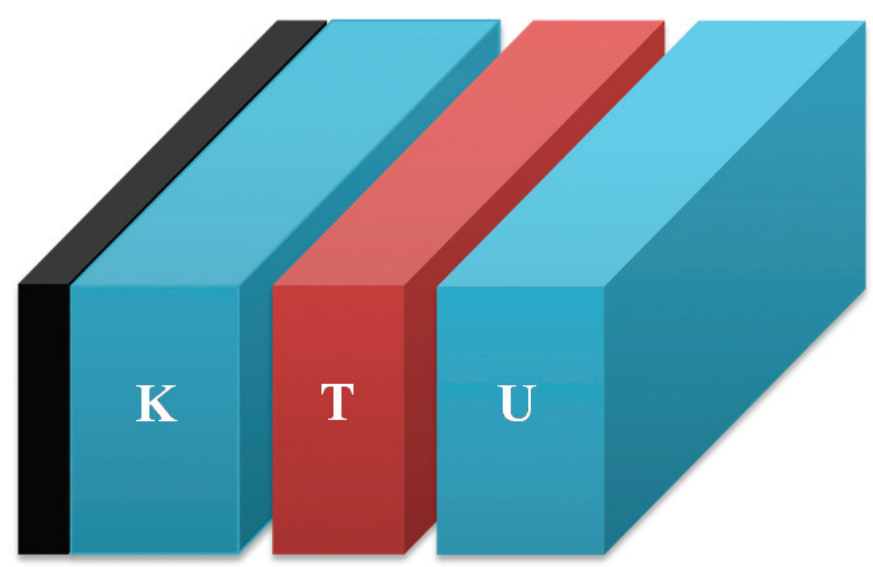

Figure 1. Scheme of structural arrangement - asymmetrical sandwich $K$ - metal plate + body of water, T explosive, $\mathrm{U}$ - closure - body of water.

the weight of which, compared with the total, is insignificant due to the weight of the water. The weight of the explosive charge (segment $\mathrm{T}$, red) is selected in order to encompass said cumulative space, and corresponds to $5 \mathrm{~kg}$. The packing volume of water (segment $\mathrm{U}$, blue) in the sandwich scheme uses a space of about 151 of water. Substituting these real values into the mathematical model using Gurney's equations shows that the velocity of the directed water jet is the coefficient value $A=1.29$ and the value of the resulting velocity of flying particles of the metal plate and water $=0.791 \mathrm{~km} / \mathrm{s}$. The performed calculation reveals that the directed jet of accelerated particles of water created by the explosion should reach speeds of $791 \mathrm{~m} / \mathrm{s}$ and at this speed then create a deactivation and elimination process during the disturbance and destruction of the bulk explosive and cause its separation from the initiation system before activation and consequent explosion.

\section{EXPERIMENTAL VERIFICATION OF SPECIAL WATER SHAPED CHARGES}

To carry out a series of five experimental field tests, several real bulk charges in van-type motor vehicles were constructed. The actual charge of explosives used was stored in tin or plastic barrels, or in plastic or paper bags [see Fig. 2, (a)]. The contents most commonly used for this purpose was an improvised type of an actual explosive based on ammonium nitrate and fuel (ANF) weighing between $600 \mathrm{~kg}$ and $800 \mathrm{~kg}$, in order to achieve the weight and volume equivalent to the presumed terrorist bombs. For realistic purposes the securing of the vehicle's cargo area against opening and unwanted entry through windows and doors was also provided. The initiation system was implemented using a remote-controlled electronic system, e.g. a remote firing system with initiators.

The structure of the water shaped charge prototype was designed in the form of a vessel for positioning a mass of water in front of explosive, and a 201 plastic canister was placed in its cumulative area [see Fig. 2, (b)]. The type of explosive used was Semtex-10 SE for its simple provisional preparation on the spot with a plasticity that is maintained over a wide temperature range, therefore its use in different climatic conditions is universal. The explosive fixed to the canister creates a directed water jet after the explosion, the purpose of 


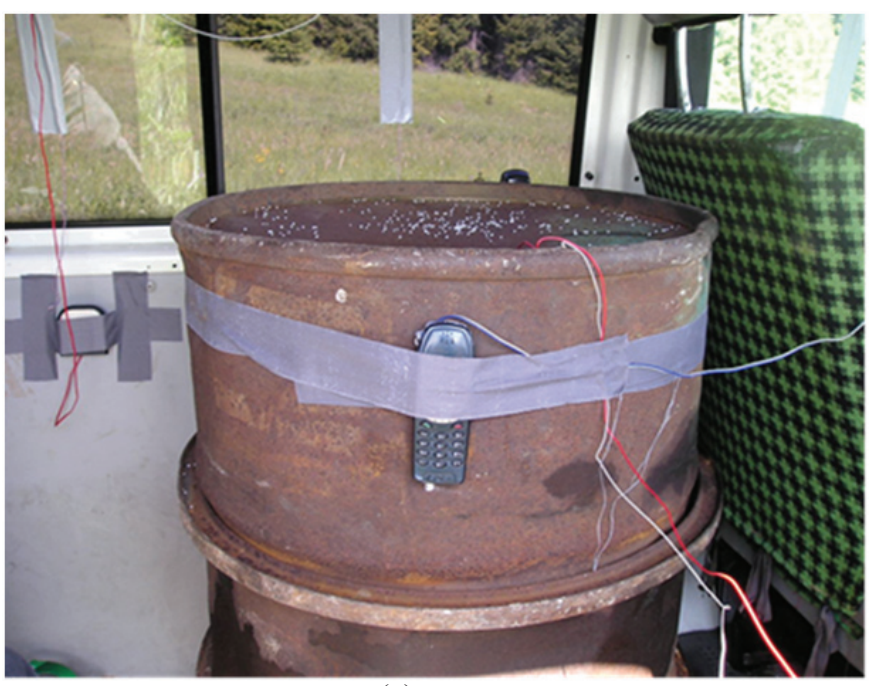

(a)

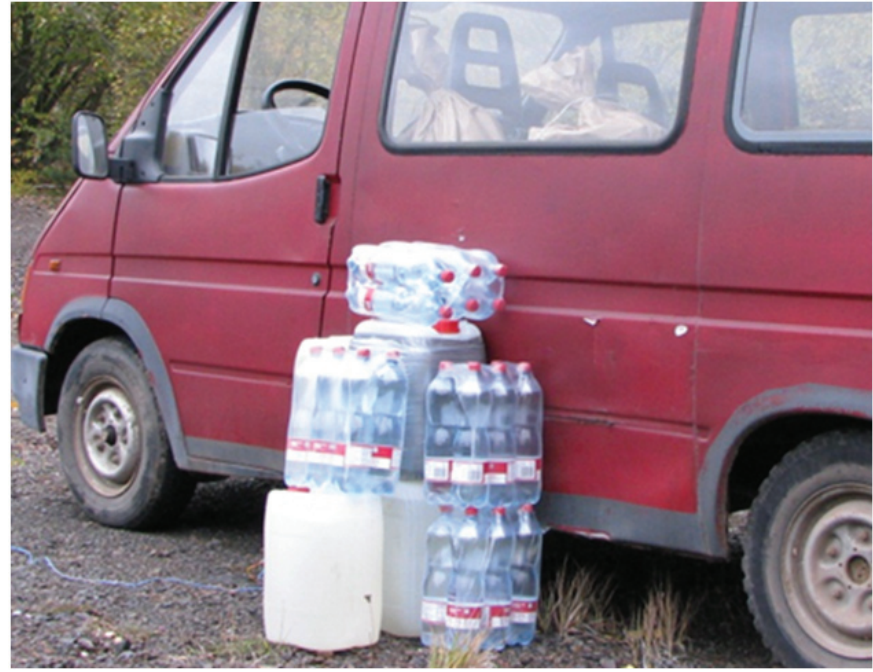

(b)

Figure 2. (a) Practical implementation of the bulk charges in barrels and (b) location of WCS by vehicle and its overall sealing with water.

which is to destroy the terrorist bomb by puncturing the metal sidewall of the vehicle, while the explosive cargo placed inside is ejected through the other side of the vehicle.

After the detonation of thus manufactured prototypes it was confirmed that in such cases water not only significantly increases the density of gas and is able to pierce the wall of the vehicle, but the directional pressurised water jets displace the charges present in the barrels or bags outside of the vehicle.

The results of the practical test are visible in Fig. 2 (b), from which it is evident that after the application of a special water shaped charge on one side of the van at the cargo area, a massive puncturing of the metal bodywork and the ejection of the barrels or bags with explosives at other side of the vehicle took place. The explosive is dispersed underneath or around the vehicles. The initiators used in the improvised initiation system were unanimously non-activated, therefore it is evident that the liquidation process upset the thus stored bulk charge so fast that the initiation system was not able to react, detonate, and cause the used explosives to blast. In the event that the

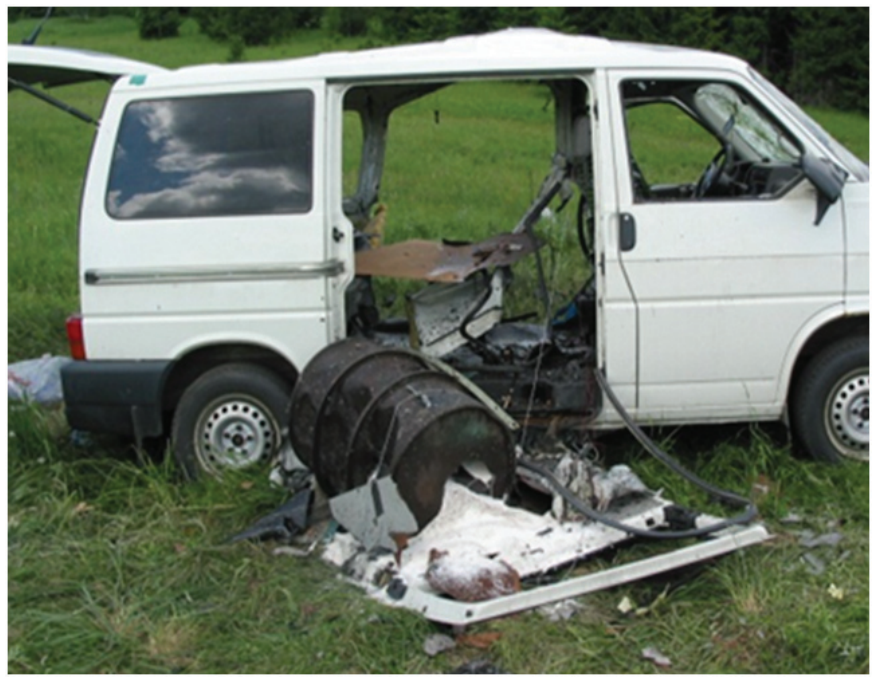

(a) response to the explosive initiators had occurred, this act would lose sense, due to the speed of the separation of explosives from them.

The rear canister with water, which served as an enclosure for directing the pressure wave forward, always created a massive water mist at the back of the WSC. This process substantially reduced the explosion temperature and suppressed the incendiary capability in the surrounding environment, see Fig. 3.

The entire process of disturbance and disposal of the bulk explosive outside the vehicle will take place in real time about $0.005 \mathrm{~s}$ to $0.050 \mathrm{~s}$ from detonation. This speed is quite sufficient to prevent activation of the initiation system used and the explosion of the charge. By approximation method of reading the positions of the water jet and the moving water droplets from a digital video image, the velocity was calculated at $625 \mathrm{~m} / \mathrm{s}$. The resulting difference between the calculated value of the velocity of the water jet $791 \mathrm{~m} / \mathrm{s}$ and the actual speed calculated from video frames may be caused

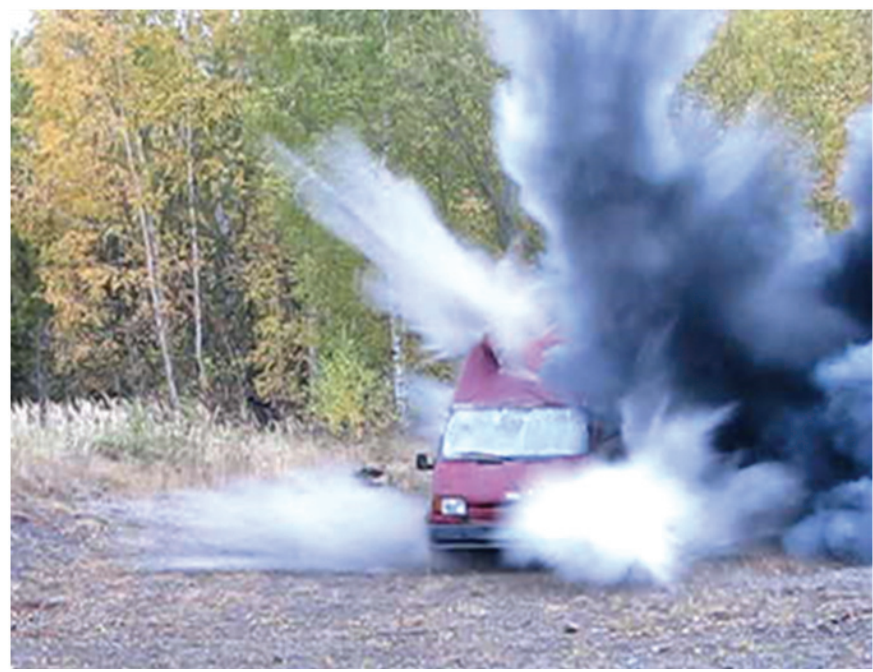

(b)

Figure 3. (a) Test results for the WCS prototype and (b) explosive flash at the time of suppression at $0.010 \mathrm{~s}$. 
by inaccuracies in reading the droplet position of a very fast and powerful directional water jet, as well as by the fact that if the sandwich arrangement is utilised, is not merely a question of an ordinary shift of the metal plate in loose positioning, but this plate, which in fact represents the metal bodywork of the vehicle, must first be separated by the explosion and then moved forward by the speed of the explosion. The detachment or puncturing of the metal plate may also cause some loss of total explosion energy, which can range up to about 30 per cent. In this case, the decrease in speed is only 21 per cent of the calculated value.

\section{CONCLUSION}

A series of experiments confirmed that the described water shaped charge with its cumulative effect can, in a very short time, effectively function against terrorist bombs placed in a motor vehicle. This procedure is not loaded with such a considerable risk as in the case of time-consuming and technically complex attempts to open and secure the utilised van with the terrorist bomb. Such a procedure would threaten the assisting bomb squad as well as others in the immediate vicinity. Using water shaped charges on the bodywork of the vehicle renders the entire defensive action faster, no explosion takes place in an exposed location, and deactivation and destruction of the explosive occurs by separation from the initiation system. This procedure will substantially increase the safety and protection of lives, health and property at the place of an anticipated terrorist bombing.

\section{REFERENCES}

1. Ericson, D.; Lacheray, H.; Lai, G. \& Haddadi, A. Multiarm multilateral haptics-based immersive tele-robotic systems (HITS) for improvised explosive device disposal. In Proceedings of SPIE, Unmanned Systems Technology XVI, Baltimore, MD, 2014. doi: 10.1117/12.2049944

2. Aviles, L.A.Z.; Szkodny, T.; Ortega, J.C.P. \& Hurtado, E.G. Systematic analysis of an IEDD unit based in a new methodology for M\&S. Int. J. Adv. Robotic Sys. 2010, 7(4), 93-100.

3. Davenport, C.; Lodmell, J.; Womble, P.C.; Barzilov, A.; Paschal, J.; Hernandez, R.; Moss, K.T. \& Hopper, L. Inexpensive semi-autonomous ground vehicles for defuzing IEDs. In: Proceedings of SPIE, Sensors and command, control, communications and intelligence (C31) technologies for homeland security and homeland defense VII, Orlando, FL, 2008.

doi: $10.1117 / 12.782988$
4. Products Alford Technologies, available on: http://explosives.net/products/technology/water-tamped/

5. Vávra, P. \& Vágenknecht, J. Theory effects of explosion. University of Pardubice, Faculty of Chemical Technology, 2004, ISBN 80-7194-494-7.

6. Cooper, P.W. \& Kurovski, S. R. Introduction to the technology of explosives. VCH Publ., USA 1996.

7. Zukas, A.J. \& Walters, W.P. Explosive effects and applications. Springer-Verlag, N.Y. 1998.

doi: 10.1007/978-1-4612-0589-0

8. Dojčár, O.; Horký, J. \& Kořínek, R. Blasting technique. Ostrava 1996, ISBN 80-85780-69-0.

9. Denhstein, J. Object protection against the effects of emergency explosions. KTTV, University of Pardubice, 1995.

\section{ACKNOWLEDGEMENTS}

This paper was developed as part of a security research project of the Czech Republic - II BV/2-VS, entitled 'The Impact of a Terrorist Attack on Selected Industrial Technologies with Potential Powder Explosion', recorded under number VG20102015059.

\section{CONTRIBUTORS}

Dr Stanislav Lichorobiec obtained his MSc degree (Radiolocation and Rocket Technology) from the Military Technical University in the Slovak Republic, and his PhD at VSB - Technical University of Ostrava, Czech Republic. Presently, he is Assistant Professor at the Department of Security Services at VSB Technical University of Ostrava. His research interests include : explosives and their destruction, the detection and disposal of improvised explosive devices, carrying out construction work and demolition using explosives. His main contribution to this publication was in the design and practical implementation of experiments in the field.

Dr Karla Barcova obtained her PhD in Solid State Physics at Palacky University in Olomouc, Czech Republic. Presently, she is Associate Professor at the Department of Security Services at VSB - Technical university of Ostrava, Czech Republic. His research interests includes; energetic materials, ballistics, applied physics. She has published more than 30 papers in various international and national journals, conferences and workshops. His contribution to this publication was in the theoretical design of experiments, mathematical calculations and design processing of assembled WSC. 